\title{
Biosynthesis of Corynecins by Corynebacterium hydrocarboclastus: On the Origin of the $\mathcal{N}$-Acyl Group
}

\author{
Hirofumi Nakano, Fusao Tomita and Takeo Suzuki* \\ Tokvo Research Laboratry, Kyowa Hakko Kogyo Co., Ltd., \\ Machida, Tokyo, Japan
}

Received September 3, 1975

\begin{abstract}
1) The addition of amino acids, such as threonine, homoserine and methionine, to producing cultures resulted in an increase of the production of Corynecin II. $a$-Ketobutyric acid showed the similar effect.

2) The incorporation of these amino acids and the ketoacid into the propionyl group of Corynecin II was confirmed by the feeding experiments with labeled compounds, whereas propionic acid-U $-{ }^{14} \mathrm{C}$ was incorporated poorly into Corynecins with a relatively high degree of randomization of radioactivities.

3) $\mathrm{L}$-Valine-U- ${ }^{14} \mathrm{C}$ was incorporated into Corynecin III, suggesting that the isobutyryl group of Corynecin III was derived from L-valine via $\alpha$-ketoisovalerate.

4) The origin of the acetyl group of Corynecin I was discussed on the basis of the incorporation experiments with acetate, pyruvate and L-alanine, all labeled with ${ }^{14} \mathrm{C}$.
\end{abstract}

Corynecins are a family of $\mathrm{N}$-acyl derivatives of $\mathrm{D}$-(-)-threo-p-nitrophenylserinol first isolated from the culture broth of Corynebacterium hydrocarboclastus. ${ }^{1)}$ Figure 1 shows chemical structure of Corynecins. The acetyl, propionyl and isobutyryl derivatives, but not the dichloroacetyl derivative (chloramphenicol), were produced under the conditions established in the previous studies. ${ }^{2 \text { ? }}$

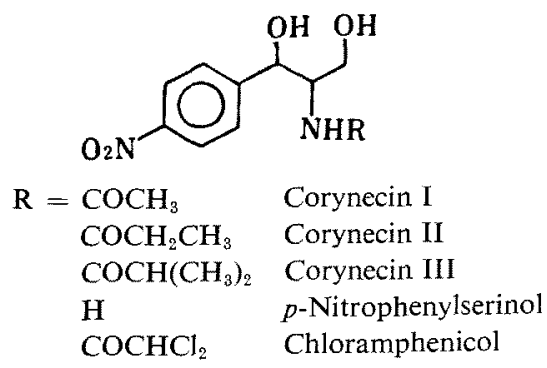

FIG. 1. Chemical Structure of Corynecins.

Recently, we reported that the inhibitory effect of Corynecins on the growth of the producer strain increased as the length of $N$-acyl side chain was increased, although

* Present address: Technical Research Laboratory, Hofu plant, Kyowa Hakko Kogyo Co., Ltd., Hofu, Yamaguchi, Japan. they were still less toxic than chlorampheni$\mathrm{col}^{3}{ }^{3)}$ Moreover, the precursor of Corynecin II, D-(-)-threo-p-aminophenylserinol- $N$-propionamide, was a potent inhibitor of biosynthesis of Corynecins from shikimic acid, but the precursor of Corynecin I, D-(-)-threo-paminophenylserinol- $N$-acetamide, was less inhibitory. " Therefore, it is important to study the biogenetic origin of the $N$-acyl groups of Corynecins for seeking rational approaches to obtain predominant producers of less toxic homologs.

We now report on the feeding experiments showing that the propionyl group of Corynecin II is derived from a-ketobutyric acid which has been formed by degradation of some amino acids. In addition, the origin of other acyl groups will be discussed on the basis of the results of the incorporation of labeled compounds.

\section{MATERIALS AND METHODS}

Strains and culture conditions. Corynebacterium hydrocarboclastus KY 8835, an excellent producer of Corynecins was used. ${ }^{5}$ ) The fermentations were carried out in the defined medium $\mathrm{CF} 8 \mathrm{M}^{4}$ ) containing sucrose, $70 ;\left(\mathrm{NH}_{4}\right)_{2} \mathrm{SO}_{4}, 5 ; \mathrm{MgSO}_{4} \cdot 7 \mathrm{H}_{2} \mathrm{O}, 1 ; \mathrm{KCl}, 8 ; \mathrm{KH}_{2} \mathrm{PO}_{4}$, 
$0.25 ; \mathrm{FeSO}_{4} \cdot 7 \mathrm{H}_{2} \mathrm{O}, 0.04 ; \mathrm{ZnSO}_{4} \cdot 7 \mathrm{H}_{2} \mathrm{O}, 0.003$; thiamine$\mathrm{HCl}, 0.01$; and inositol, 0.08 ; all in $\mathrm{g} /$ liter.

Labeled compounds. Shikimic acid-U $-{ }^{14} \mathrm{C}$ and sodium propionate- $2-{ }^{14} \mathrm{C}$ were obtained from $\mathrm{New}$ England Nuclear Corp. Sodium pyruvate-U ${ }^{14} \mathrm{C}$ was obtained from Amersham. DL- $\alpha$-Amino butyrate-3- ${ }^{14} \mathrm{C}$ was obtained from Radioelement, C.E.A. L-Threonine$\mathrm{U}-{ }^{14} \mathrm{C}$, L-glutamic acid-U- ${ }^{14} \mathrm{C}$, L-alanine-U- ${ }^{14} \mathrm{C}$, Lvaline-U $-{ }^{14} \mathrm{C}$ and sodium acetate- $2{ }^{-14} \mathrm{C}$ were obtained from Daiichi Pure Chemicals Co.

Addition of labeled compounds. In most experiments, labeled substrates were diluted with the solution containing $20 \mathrm{~mm}$ unlabeled compounds to make the specific activity close to $10 \mu \mathrm{Ci} / 20 \mathrm{~mm}$. The solution of radioactive supplement $(0.2 \mathrm{ml})$ was added to the producing culture $(1.8 \mathrm{ml})$ at the time after $72 \mathrm{hr}$ of incubation in a $20-\mathrm{ml}$ test tube, and shaken at $30^{\circ} \mathrm{C}$. After further $24 \mathrm{hr}$ of incubation the cells were removed by centrifugation.

Analytical procedures. The supernatants obtained as above were mixed with carrier Corynecins, and then applied on Silicagel $G$ plates (Merck) and developed with a mixture of $\mathrm{CHCl}_{3}$ and methanol (90:10, v/v). The Corynecin homologs were detected by exposing the plates over an ultraviolet lamp and the radioactivity of each spot was measured with a liquid scintillation counter. To measure the radioactivities of the remaining substrates, the supernatants with carriers were separated by paper chromatography with the solvent systems, (A) $n$-butanol: acetic acid: water $(12: 3: 5)$ and (B) ethanol: ammonia: water $(18: 1: 1)$. The spots of substrates were detected by their ultraviolet absorbance or the coloration with the ninhydrin reagent.

Bacterial cell growth and the total amount of Corynecins were assayed as described previously., ${ }^{6,7)}$ Corynecins I, II and III were separated by thin-layer chromatography and the amounts of each component were determined by measuring the intensity of absorbance at $278 \mathrm{~nm}$ with a Shimadzu CS-900 chromatoscanner. Radioactivities were measured as described in the previous paper. ${ }^{4}$ The concentration of inorganic phosphate in the medium was estimated by the method of Chen. $\left.{ }^{8}\right)$

\section{RESULTS}

Effect of amino acids and organic acids on the composition of products

Figure 2 shows a typical time course of Corynecin production in the defined medium CF8M. The accumulation of Corynecins began after about $24 \mathrm{hr}$ and continued in parallel to the cell growth until the sucrose was exhausted. Throughout the production phase, the accumulation rate of Corynecins remained constant and the ratios of the each component were also unaltered. Thus, feeding of precursors of acyl group to the producing culture would result in an increase of the ratio of the corresponding Corynecin component.

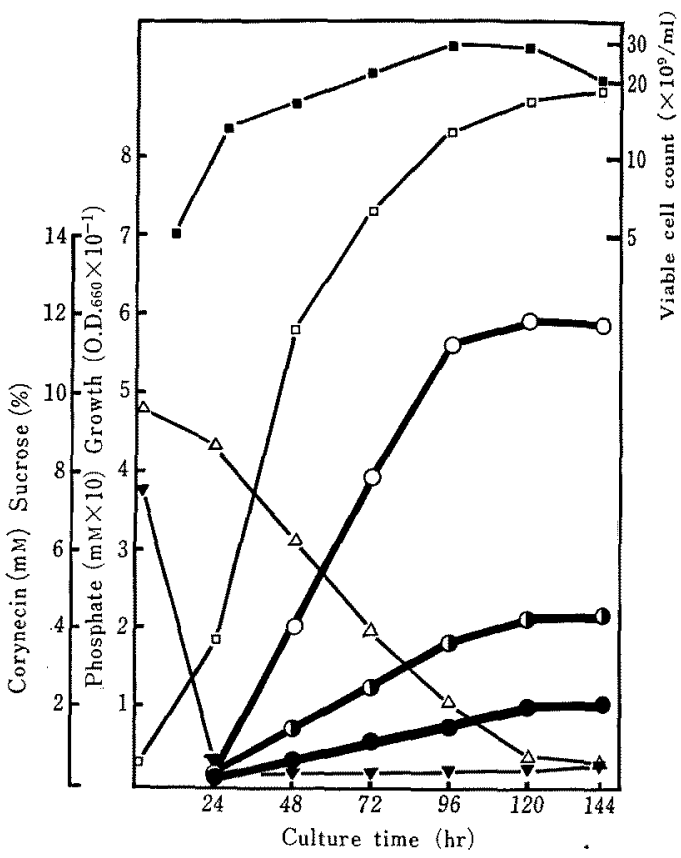

FIG. 2. Time Course of Corynecin Fermentation in the Medium CF 8M.

O, Corynecin I; Corynecin II;, Corynecin III. $\square$, growth (O.D.); $\square$, viable cell count; $\triangle$, residual sucrose; $\boldsymbol{\nabla}$, residual phosphate.

While the effect of amino acids and organic acids on Corynecin production was studied, it was found that threonine, homoserine, $\alpha$ aminobutyric acid and $\alpha$-ketobutyric acid caused an increase of the ratio of Corynecin II, as shown in Table I. These results suggested that the propionyl group of Corynecin II was derived from oxidative decarboxyration of $\alpha$-ketobutyric acid which had been formed by degradation of such amino acids as threonine, homoserine and methionine.

However, alanine, a conceivable precursor of the acetyl group of Corynecin I, did not show the effect of increasing the ratio of Corynecin II, whereas lysine showed the effect 
TABle I. EFFect of Amino Acids AND Keto Acid on Corynecin Production

Each compound was added to the culture broth at $48 \mathrm{hr}$ and incubation was continued further at $30^{\circ} \mathrm{C}$ with shaking for $36 \mathrm{hr}$.

\begin{tabular}{|c|c|c|c|}
\hline \multirow{2}{*}{ Addition } & \multirow{2}{*}{$\begin{array}{c}\text { Conc. } \\
(\mathrm{mg} / \mathrm{ml})\end{array}$} & \multirow{2}{*}{$\begin{array}{l}\text { Total Coryne- } \\
\text { cins as } l \text {-base } \\
\left.(\mathrm{mg} / \mathrm{ml})^{a}\right)\end{array}$} & \multirow{2}{*}{$\frac{\text { Corynecin I }}{\text { Corynecin II }}$} \\
\hline & & & \\
\hline \multirow[t]{5}{*}{ L-Threonine } & 10 & 0.95 & 0.11 \\
\hline & 5 & 1.02 & 0.95 \\
\hline & 2 & 1.31 & 2.0 \\
\hline & 1 & 1.52 & 2.4 \\
\hline & 0.5 & 1.45 & 2.4 \\
\hline \multirow[t]{5}{*}{ L-Homoserine } & 10 & 1.04 & 0.1 \\
\hline & 5 & 1.10 & 0.1 \\
\hline & 2 & 1.28 & 1.7 \\
\hline & 1 & 1.28 & 1.7 \\
\hline & 0.5 & 1.52 & 2.3 \\
\hline \multirow[t]{5}{*}{ ¿-Aminobutyrate } & 10 & 1.06 & 0.14 \\
\hline & 5 & 1.19 & 0.10 \\
\hline & 2 & 1.06 & 0.19 \\
\hline & 1 & 1.20 & 0.99 \\
\hline & 0.5 & 1.40 & 1.9 \\
\hline \multirow[t]{3}{*}{$\alpha$-Ketobutyrate } & 10 & 0.84 & 0.26 \\
\hline & 5 & 1.04 & 1.5 \\
\hline & 1 & 1.35 & 2.7 \\
\hline L-Alanine & 5 & 1.02 & 2.3 \\
\hline D-Alanine & 5 & 1.00 & 2.3 \\
\hline L-Lysine & 5 & 1.56 & 3.4 \\
\hline L-Methionine & 5 & 1.00 & 0.6 \\
\hline None & & 1.27 & 2.7 \\
\hline
\end{tabular}

a) Since the amount of Corynecin homologs produced varied depending on culture conditions, the total Corynecins produced were expressed as the concentration of $p$-nitrophenylserinol ( $l$ base, the free base of Corynecins).

of increasing that of Corynecin I. It is likely that the addition of lysine to the producing culture causes the depression of the biosynthesis of amino acids belonging to the aspartate family.

It is possible, however, that the addition of amino acids as high as $0.5 \%$ affect the biosynthesis of Corynecin in CF8M containing sucrose as a sole carbon source. Thus, the incorporation of these amino acids into Corynecin was studied further with the labeled compounds.

Incorporation of labeled compounds into Corynecin

A) Amino acids. The incorporation data
TABLE II. INCORPORATION OF LABELED COMPOUNDS INTO CORYNECINS

Labeled compounds $(0.2 \mathrm{ml}$ of $20 \mu \mathrm{mole} / \mathrm{ml}$ containing $10 \mu \mathrm{Ci}$ ) were administered to $1.8 \mathrm{ml}$ of the culture broth after 72 -hr incubation and incubation was continued further with shaking at $30^{\circ} \mathrm{C}$ for $24 \mathrm{hr}$. After centrifugation, the supernatants were analyzed as described in the text.

\begin{tabular}{|c|c|c|c|c|}
\hline \multirow{2}{*}{$\begin{array}{l}\text { Labeled } \\
\text { compounds }\end{array}$} & \multirow{2}{*}{$\operatorname{Uptake}^{a)}$} & \multicolumn{3}{|c|}{$\%$ incorporation $\left.{ }^{b}\right)$ into } \\
\hline & & Cory I & Cory II & Cory III \\
\hline L-Valine-U-14C & 98 & 1.4 & 11.5 & \\
\hline $\mathrm{L}-\mathrm{Th}$ reonine- $\mathrm{U}-{ }^{14} \mathrm{C}$ & C 98 & 0.9 & 9 & 0.8 \\
\hline L-Glutamate-U ${ }^{14} \mathrm{C}$ & C 99 & 1.0 & 2.0 & 0.4 \\
\hline $\mathrm{I}-$ Alanine- $\mathrm{U}-{ }^{14} \mathrm{C}$ & 99 & 4.2 & 2.0 & 0.6 \\
\hline $\begin{array}{l}\text { DL- } \alpha \text {-Amino- } \\
\text { butyrate- } 3 *{ }^{14} \mathrm{C}\end{array}$ & 60 & & 52.0 & 0.9 \\
\hline Pyruvate & 96 & 0.8 & 0.5 & 0.2 \\
\hline
\end{tabular}

a) $\{$ (Radioactivity added)-(Radioactivity of the remaining compound) $\times 100 /$ (Radioactivity added)

b) (Radioactivity in Corynecin) $\times 100 /\{$ (Radioactivity added) - (Radioactivity of the remaining compound)\}

(Table II) show that $\alpha$-aminobutyric acid and threonine were effectively incorporated into Corynecin II and valine into Corynecin III. Although about $4 \%$ of the radioactivity of alanine- $\mathrm{U}-{ }^{14} \mathrm{C}$ was recovered in Corynecin $\mathrm{I}$, a relatively high degree of randamization occurred under these conditions.

To obtain further evidence for the role of these amino acids and keto acid as a specific precursor of Corynecin, samples of Corynecin produced in the presence of DL- $\alpha$-aminobutyrate- $3-{ }^{14} \mathrm{C}$ were degraded to the acyl group and $p$-nitrophenylserinol by both alkaline and acid hydrolyses.

The labeled Corynecins were extracted as described in the previous report, ${ }^{4}$ and then they were degraded with both acid and alkali. The acid hydrolysis of Corynecins and the crystallization of $p$-nitrophenylserinol were carried out as described previously. ${ }^{4}$ To recover the acyl groups, the labeled Corynecins $(200 \mathrm{mg})$ were heated in hot water $\left(75 \sim 80^{\circ} \mathrm{C}\right)$ with $1 \mathrm{~N} \mathrm{NaOH}(10 \mathrm{ml})$ for $2.5 \mathrm{hr}$. The cooled reaction mixture was adjusted to $\mathrm{pH} 10$ with $2 \mathrm{~N} \mathrm{HCl}$, and the precipitate was removed by filtration. The filtrate was applied on a column 
of neutral polystyrene resin (HP-10, Mitsubishi Kasei Co.), and the eluates with methanol were evaporated to dryness. The data from these degradation experiments showed that almost all of the radioactivity in the Corynecin II which had been synthesized in the presence of DL- $\alpha$-aminobutyrate- $3-{ }^{14} \mathrm{C}$ was located in the acyl group, in contrast to the case of the Corynecin synthesized in the presence of shikimic acid-U- ${ }^{14} \mathrm{C}$ (Table III).

B) Organic acid. Table IV shows that the radioactivity from $\mathrm{L}$-threonine- $\mathrm{U}-{ }^{14} \mathrm{C}$ was predominantly found in Corynecin II, whereas the incorporation of propionate- $2-{ }^{14} \mathrm{C}$ was low in efficiency (about $5 \%$ ) and the extent of distribution in Corynecin II was markedly low comparing with the case of threonine.

TABLE III. Distribution OF RAdIOACTIVITY IN CORYNECINS INCORPORATED FROM ${ }^{14} \mathrm{C}$ LABeled Precursors

A) Acid hydrolysis

\begin{tabular}{|c|c|c|c|}
\hline \multirow[b]{2}{*}{ Precursor } & \multirow{2}{*}{$\begin{array}{l}\text { Corynecins } \\
\mathrm{nCi} / \mathrm{mmole}\end{array}$} & \multicolumn{2}{|c|}{$p$-Nitrophenylserinol } \\
\hline & & $\begin{array}{c}\mathrm{nCi} / \mathrm{m} \\
\text { mole }\end{array}$ & $\begin{array}{c}\% \text { of } \\
\text { Corynecins }\end{array}$ \\
\hline Shikimate- $\mathrm{U}-{ }^{14} \mathrm{C}$ & 59 & 60 & 100 \\
\hline $\begin{array}{l}\text { DL- } \alpha \text {-Amino- } \\
\text { butyrate- } 3-{ }^{14} \mathrm{C}\end{array}$ & 1300 & 1.4 & 0.1 \\
\hline
\end{tabular}

B) Alkaline hydrolysis

\begin{tabular}{|c|c|c|c|}
\hline \multirow[t]{2}{*}{ Precursor } & \multirow{2}{*}{$\begin{array}{c}\text { Total activity } \\
\text { in Corynecins } \\
\mathrm{cpm}\end{array}$} & \multicolumn{2}{|c|}{$\begin{array}{l}\text { Total activity } \\
\text { recovered as } \\
\text { RCOO-Na }\end{array}$} \\
\hline & & $\operatorname{cpm} \% \mathrm{c}$ & Corynecins \\
\hline Shikimate-U ${ }^{14} \mathrm{C}$ & $3.9 \times 10^{4}$ & $1 \times 10^{2}$ & 0.1 \\
\hline $\begin{array}{l}\text { DL- } \alpha \text {-Amino- } \\
\text { butyrate- } 3-{ }^{14} \mathrm{C}\end{array}$ & $8.6 \times 10^{5}$ & $2.8 \times 10^{5}$ & 32.5 \\
\hline
\end{tabular}

a) After alkaline hydrolysis p-nitrophenylserinol was removed by column chromatography, and RCOO-Na was recovered by evaporating the effluent. Their recoveries were not quantitative.

Acetate- $2-{ }^{14} \mathrm{C}$ was incorporated into both Corynecin I and Corynecin II in a low efficiency, and the ratio of Corynecin I to Corynecin II was similar to that in the case of shikimate$\mathrm{U}^{-14} \mathrm{C}$. Taking account of the ratio of Corynecin I to Corynecin II produced from sucrose
Table IV. Distribution OF Radioactivity IN Corynecins Produced in the Presence of VARIOUS LABELED COMPOUNDS

Labeled compounds were administrated as described in Table II. The radioactivities in Corynecins were measured as described in MATERIALS AND Methods.

\begin{tabular}{|c|c|c|c|}
\hline \multirow{2}{*}{$\begin{array}{l}\text { Labeled } \\
\text { compounds }\end{array}$} & \multicolumn{2}{|c|}{$\%$ incorporation into } & \multirow{2}{*}{ 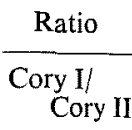 } \\
\hline & Cory I & Cory II & \\
\hline Shikimate-U- ${ }^{14} \mathrm{C}$ & 2.5 & 1.7 & 1,47 \\
\hline L-Threonine-U- ${ }^{14} \mathrm{C}$ & 1.6 & 32.0 & 0.05 \\
\hline Propionate $-2 \cdot{ }^{14} \mathrm{C}$ & 2.6 & 3.0 & 0.85 \\
\hline Acetate-2- ${ }^{14} \mathrm{C}$ & 2.3 & 1.5 & 1.54 \\
\hline
\end{tabular}

in CF8M, the added acetate was not incorporated directly into the acetyl group of Corynecin I, but it was metabolized via the tricarboxylic acid cycle and then incorporated into Corynecin I. The distribution of radioactivity in the Corynecin I synthesized in the presence of propionate- $2-{ }^{14} \mathrm{C}$ suggested that a large portion of the added propionate also passed through the common metabolic cycles in cells of the producing phase.

\section{DISCUSSION}

In the biosynthesis of Corynecin, shikimic acid was a precursor of the aromatic ring of Corynecin," and $N$-acyl derivatives of $p$ aminophenylalanine were present in the producing culture. These results suggest that the $N$-acyl group of Corynecins is formed at the step of $p$-aminophenylalanine. ${ }^{9} \quad$ Thus, the mechanism of the $N$-acylation can be considered to be a similar manner as in the case of $N$-acyl amino acids.

The formation and excretion of $\mathrm{N}$-acyl derivatives of amino acids have long been known, and the intermediate acylation agents were shown to be the corresponding acyl-CoA: The major sources of acyl-CoA were known to be derived from either $\beta$-oxidation of long chain fatty acids, oxidative decarboxylation of $\alpha$-keto acids or activation reaction of corresponding organic acids by thiokinase or thiophorase. 
The earlier results ${ }^{6}$ from our laboratory have shown that the amounts of Corynecin I and Corynecin II produced differed distinctly with the carbon number of $n$-alkane employed as a carbon source; odd-numbered alkanes gave a large amount of Corynecin II. The acyl-CoA derived from $\beta$-oxidation would be incorporated into the acyl group of Corynecins. However, the acyl group of Corynecins would mainly arise from another pathway, because (1) in spite of the diversity in carbon numbers, Corynecin II was produced predominantly in the $n$-alkane medium, (2) the amount of Corynecin I produced was significantly higher in the sucrose medium than in the $n$-alkane medium, (3) degradation of cellular fatty acids could not be regarded as a significant source of acyl-CoA, because both the turbidity of culture broth and the viable cell counts increased throughout the production phase as shown in Fig. 2, and (4) the isobutyryl derivative (Corynecin III) was produced from straight-chain $n$-alkanes. Therefore, the acyl-CoA derived from $\beta$-oxidation could not be considered as a major origin of the acyl group of Corynecins.

On the other hand, as shown in this report, the addition of exogeneous amino acids such as threonine, homoserine and methionine to the sucrose medium resulted in an increase of Corynecin II, and $\alpha$-keto butyric acid also increased the production of Corynecin II.

The incorporation of these amino acids and $\alpha$-keto butyric acid into the propionyl group of Corynecin II was confirmed further by the feeding experiments with labeled compounds. Thus, oxidative decarboxylation of $\alpha$-keto acids appears to be a principal source of the propionyl group of Corynecin II.

The incorporation data of $\mathrm{L}$-valine- $\mathrm{U}-{ }^{14} \mathrm{C}$ into Corynecin III revealed that the isobutyryl group of Corynecin III was also derived from oxidative decarboxylation of $\alpha$-keto isovaleric acid. The considerable incorporation of the radioactivity from $L$-valine into Corynecin II could be regarded as a result of further degradation of isobutyryl-CoA to propionyl-CoA through methylmalonyl-CoA.
No conclusion could be drawn from the present results on the source of the acetyl group of Corynecin $\mathrm{I}$, since all the radioactivity from acetic acid- $\mathrm{U}_{-14}^{14} \mathrm{C}$, pyruvic acid-U${ }^{14} \mathrm{C}$ and L-alanine- $\mathrm{U}_{-}{ }^{14} \mathrm{C}$ was distributed in Corynecin I and Corynecin II in a similar ratio (Tables II and IV).

Activation reaction of corresponding organic acids did not appear to play an important part in the biosynthesis of the acyl group of Corynecins in the sucrose medium (Table IV). As pointed out in the study of the tetracycline biosynthesis, ${ }^{10}$ to convert the organic acid added to the medium to the corresponding acyl-CoA, cells require considerable energies that must be obtained from the cleavage of ATP or markedly exergonic reactions. In the fermentation medium CF8M used in the present experiments, the concentration of phosphate was extremely low, and inorganic phosphate was exhausted from the medium before the beginning of the production of Corynecins. Therefore, under these conditions, activation reactions may not play a principal role in the biosynthesis of acyl-CoA.

So long as Corynecins were produced under the conditions described above, it was difficult to decrease the production of Corynecin II and Corynecin III, which are undesirable to increase the total amounts of Corynecins produced. However, we found recently that reduced production of Corynecin II and III and a simultaneous increase of the total Corynecin production can be obtained in a medium containing a higher concentration of phosphate and acetic acid as a sole carbon source. ${ }^{11 /}$

\section{REFERENCES}

1) T. Suzuki, H. Honda and R. Katsumata, Agr. Biol. Chem., 36, 2223 (1972).

2) K. Shirahata, T. Hayashi, T. Deguchi, T. Suzuki and I. Matsubara, ibid., 36, 2229 (1972).

3) F. Tomita, H. Nakano, H. Honda and T. Suzuki, ibid., 38, 2183 (1974).

4) H. Nakano, F. Tomita and T. Suzuki, ibid., 38, 2505 (1974).

5) H. Nakano, F. Tomita and T. Suzuki, ibid., 38, 2471 (1974). 
6) F. Tomita, H. Nakano and T. Suzuki, Agr. Biol. Chem., 38, 1673 (1974).

7) T. Suzuki, F. Tomita and H. Nakano, ibid., 38, 2477 (1974).

8) P. S. Chen, Anal. Chem., 28, 1756 (1956).

9) H. Nakano, F. Tomita and T. Suzuki, Agr. Biol.
Chem., 40, 207 (1976).

10) Z. Vanek, Z. Hostalek, M. Blumauerova, K. Mikulik, M. Podojil, V. Behal and V. Jechova, Pure Appl. Chem., 34, 463 (1973).

11) H. Nakano, F. Tomita and T. Suzuki, in preparation. 